\title{
A Micromechanics-Based Model for Stiffness and Strength Estimation of Cocciopesto Mortars
}

\author{
Václav Nežerka, Jan Zeman \\ Department of Mechanics, Faculty of Civil Engineering, Czech Technical University in Prague, Thákurova 7, 166 29 \\ Praha 6, Czech Republic
}

Corresponding author: vaclav.nezerka@fsv.cvut.cz, zemanj@cml.fsv.cvut.cz

\begin{abstract}
The purpose of this paper is to propose an inexpensive micromechanics-based scheme for stiffness homogenization and strength estimation of mortars containing crushed bricks, known as cocciopesto. The model utilizes the Mori-Tanaka method for determining the effective stiffness, combined with estimates of quadratic invariants of the deviatoric stresses inside phases to predict the compressive strength. Special attention is paid to the representation of the C-S-H gel layer around bricks and the interfacial transition zone around sand aggregates, which renders the predictions sensitive to particle sizes. Several parametric studies are performed to demonstrate that the method correctly reproduces the data and trends reported in the available literature. Moreover, the model is based exclusively on parameters with a clear physical or geometrical meaning, and as such it provides a convenient framework for its further experimental validation.
\end{abstract}

Keywords: micromechanics, homogenization, strength estimation, cocciopesto, C-S-H gel coating, interfacial transition zone.

\section{Introduction}

The use of lime as a binder in mortars is associated with well-known inconveniences, such as slow setting and carbonation, high drying shrinkage and porosity, and low mechanical strength [1]. Although these limitations have been overcome with the use of Portland cement in the last 50 years, lime mortars still find use in the restoration of historic structures. This is mainly due to their superior compatibility with the original materials, in contrast to many modern renovation render systems, e.g. [16, 17, 29].

The mechanical properties of lime mortars can be improved by the suitable design of the mixture. The Phoenicians were probably the first ones to add crushed clay products, such as burnt bricks, tiles or pieces of pottery, to lime mortars to increase their durability and strength. The Romans called this material cocciopesto and utilized this mortar in areas where other natural pozzolans were not available. Cocciopesto-based structures exhibit increased ductility, leading to their remarkable resistance to earthquakes [3, 21].

Much later, it was found that the mortars containing crushed clay bricks, burnt at $600-900^{\circ} \mathrm{C}$, exhibit a hydraulic character, manifested by the formation of a thin layer of Calcium-Silicate-Hydrate (C-S-H) gel at the lime-brick interface [20]. Since C-S-H gel is the key component responsible for the favorable mechanical performance of Portland cement pastes [23], it is generally conjectured that the enhanced performance of cocciopesto mortars can be attributed to the high strength and stiffness of the C-S-H gel coating $[3,20,21,29]$. This mechanism competes with the formation of the Interfacial Transition Zone (ITZ) at the matrix-aggregate interface, which is known to possess higher porosity and thus lower stiffness in cement-based mortars, e.g. [24, 28, 36].

The purpose of this work is to interpret these experimental findings by a micromechanical model based on the Mori-Tanaka method [19], motivated by its recent applications to related material systems. These include estimates of the effective thermal conductivity of rubber-reinforced cement composites [31], elasticity predictions for early-age cement [5] or alkali-activated [35] pastes, upscaling the compressive strength of cement mortars [26], and multi-scale simulations of three-point bending tests of concrete specimens [34]. Here, we exploit these developments to propose a simple analytical model for a stiffness and strength estimation of cocciopesto mortars in Section 2. In particular, the elasticity predictions utilize Benveniste's reformulation [4] of the Mori-Tanaka method [19], whereas the strength predictions build on recent results by Pichler and Hellmich [26], who demonstrated that compressive strength is closely related to the quadratic average of the deviatoric stress in the weakest phase. Particular attention is paid to representation of the coatings by C-S-H gel and ITZ, which renders the predictions sensitive to the size of the brick particles and aggregates. In Section 3, we verify predictions of the proposed scheme against data available in the open literature. These finding are summarized in Section 4, mainly as a support for 


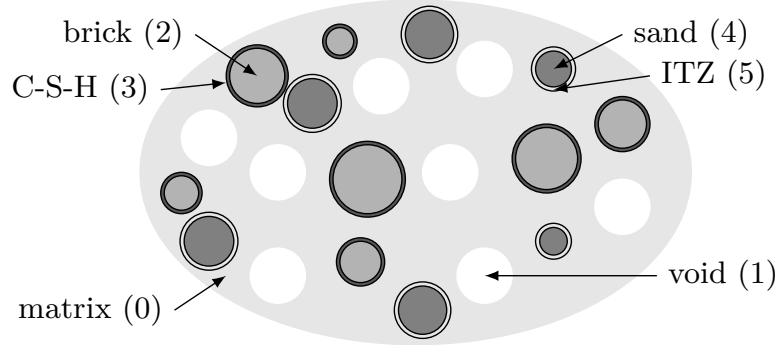

Figure 1: Scheme of the micromechanics-based model. The numbers in parentheses refer to the indexes of the individual phases.

future validation of the model against experimental results. Finally, in Appendix A we gather technical details needed to account for coated inclusions in order to make the paper self-contained.

In what follows, the Mandel representation of symmetric tensorial quantities is systematically employed, e.g. [18, p. 23]. In particular, italic letters, e.g. $a$ or $A$, refer to scalar quantities, and boldface letters, e.g. $\boldsymbol{a}$ or $\boldsymbol{A}$, denote vectors or matrix representations of second- or fourth-order tensors. $\boldsymbol{A}^{\top}$ and $(\boldsymbol{A})^{-1}$ standardly denote the matrix transpose and the inverse matrix. Other symbols and abbreviations are introduced in the text when needed.

\section{Model}

We consider a composite sample occupying domain $\Omega$, composed of $n$ distinct phases indexed by $r$. The value $r=0$ is reserved for the matrix phase and $r=1, \ldots, n$ refer to heterogeneities having the shape of a sphere or spherical shell, see Fig. 1. The volume fraction of the $r$-th phase is defined as $c^{(r)}=\left|\Omega^{(r)}\right| /|\Omega|$, where $\left|\Omega^{(r)}\right|$ denotes the volume occupied by the $r$-th phase, and the geometry of the coated particles is specified by their radii $R^{(r)}$ for $r=2, \ldots, 5$, Fig. 2 .

Several comments are in now order concerning simplifications adopted in the model. First, brick particles and voids are considered spherical in shape, instead of more realistic ellipsoids, as in e.g. [27, 26]. This step is known to introduce only minor errors in the prediction of overall transport [31] or elastic [27] properties. As demonstrated by Pichler et al. [27], the up-scaled strength is more sensitive to the shape of inhomogeneities, but the model is still capable of predicting the correct trends. Second, the ITZ is taken as homogeneous and is not resolved down to the level of microheterogeneities. This arises as a result of the fact that, in contrast to cement-based materials [24, 28], we are currently not aware of any work studying the structure of ITZ in lime-based mortars, thus input data for a more detailed representation is not available. Third, only monodisperse distribution of particles in assumed. Polydispersivity can be incorporated by sim- ple averaging arguments and results only in a moderate increase in accuracy [31, and references therein].

The elastic properties of the individual phases are specified by the material stiffness matrix $\boldsymbol{L}^{(r)}$. As each phase is assumed to be homogeneous and isotropic, we have

$$
\boldsymbol{L}^{(r)}=3 K^{(r)} \boldsymbol{I}_{\mathrm{V}}+2 G^{(r)} \boldsymbol{I}_{\mathrm{D}} \quad \text { for } r=0, \ldots, n,
$$

where $K^{(r)}$ and $G^{(r)}$ are the bulk and shear moduli of the $r$-th phase, and $\boldsymbol{I}_{\mathrm{V}}$ and $\boldsymbol{I}_{\mathrm{D}}$ denote the orthogonal projections to the volumetric and deviatoric components, e.g. [13], so that

$$
\begin{gathered}
\boldsymbol{\varepsilon}(\boldsymbol{x})=\left(\boldsymbol{I}_{\mathrm{V}}+\boldsymbol{I}_{\mathrm{D}}\right) \boldsymbol{\varepsilon}(\boldsymbol{x})=\varepsilon_{\mathrm{V}}(\boldsymbol{x}) \mathbf{1}+\varepsilon_{\mathrm{D}}(\boldsymbol{x}), \\
\boldsymbol{\sigma}(\boldsymbol{x})=\left(\boldsymbol{I}_{\mathrm{V}}+\boldsymbol{I}_{\mathrm{D}}\right) \boldsymbol{\sigma}(\boldsymbol{x})=\sigma_{\mathrm{V}}(\boldsymbol{x}) \mathbf{1}+\boldsymbol{\sigma}_{\mathrm{D}}(\boldsymbol{x}),
\end{gathered}
$$

for $\boldsymbol{x} \in \Omega$. In Eq. (2), $\boldsymbol{\varepsilon}$ and $\boldsymbol{\sigma}$ refer to local stresses and strains, $\varepsilon_{\mathrm{V}}$ and $\varepsilon_{\mathrm{D}}$ are the volumetric and deviatoric strain components, $\sigma_{\mathrm{V}}$ and $\boldsymbol{\sigma}_{\mathrm{D}}$ refer to the stress components, and $\mathbf{1}$ is the second-order unit tensor (in the matrix representation).

The development of the model follows the standard routine of the continuum micromechanics, e.g. [37]. The sample $\Omega$ is subjected to the overall strain loading $\boldsymbol{E}$. Neglecting the interaction among the phases, the mean strains inside the heterogeneities are obtained as

$$
\boldsymbol{E}^{(r)}=\boldsymbol{A}_{\mathrm{dil}}^{(r)} \boldsymbol{E} \quad \text { for } r=1, \ldots, n,
$$

where $\boldsymbol{A}_{\mathrm{dil}}^{(r)}$ is the dilute concentration factor of the $r$-th phase, see Section 2.1. In Section 2.2, after accounting for the phase interaction, these are combined to the full concentration factors satisfying

$$
\boldsymbol{E}^{(r)}=\boldsymbol{A}^{(r)} \boldsymbol{E} \quad \text { for } r=0, \ldots, n
$$

utilized next to estimate the overall stiffness of the composite material, $\boldsymbol{L}_{\text {eff }}$. Moreover, as outlined in Section 2.3, the expression for the overall stiffness also encodes the mean value of the quadratic invariant of the local stress deviator $\boldsymbol{\sigma}_{\mathrm{D}}$, defined as

$$
J_{2}^{(r)}=\sqrt{\frac{1}{2\left|\Omega^{(r)}\right|} \int_{\Omega^{(r)}} \boldsymbol{\sigma}_{\mathrm{D}}(\boldsymbol{x})^{\top} \boldsymbol{\sigma}_{\mathrm{D}}(\boldsymbol{x}) \mathrm{d} \boldsymbol{x}},
$$

which can be directly used to estimate the overall strength of a material.

\subsection{Dilute concentration factors}

Due to the geometrical and material isotropy of the individual phases, the dilute concentration factors attain a form analogous to (1):

$$
\boldsymbol{A}_{\mathrm{dil}}^{(r)}=A_{\mathrm{dil}, \mathrm{V}}^{(r)} \boldsymbol{I}_{\mathrm{V}}+A_{\mathrm{dil}, \mathrm{D}}^{(r)} \boldsymbol{I}_{\mathrm{D}} \text { for } r=1, \ldots, n .
$$




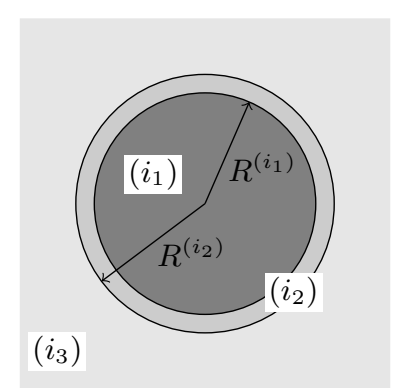

Figure 2: Scheme of a single-layer inclusion

The expressions for the components are given separately for the uncoated $(r=1)$ and coated $(r=$ $2, \ldots, 5)$ particles. Namely, in the first case it holds

$$
\begin{aligned}
& A_{\mathrm{dil}, \mathrm{V}}^{(1)}=\frac{K^{(0)}}{K^{(0)}+\alpha^{(0)}\left(K^{(1)}-K^{(0)}\right)}, \\
& A_{\mathrm{di}, \mathrm{D}}^{(1)}=\frac{G^{(0)}}{G^{(0)}+\beta^{(0)}\left(G^{(1)}-G^{(0)}\right)},
\end{aligned}
$$

with the auxiliary factors following from the Eshelby solution [9] in the form

$$
\alpha^{(0)}=\frac{1+\nu^{(0)}}{3\left(1+\nu^{(0)}\right)}, \quad \beta^{(0)}=\frac{2\left(4-5 \nu^{(0)}\right)}{15\left(1-\nu^{(0)}\right)},
$$

where $\nu^{(0)}$ is the Poisson ratio of the matrix phase.

The coated case is more involved, and was first solved in its full generality by Herve and Zaoui [10] for a multi-layered spherical inclusion. To apply their results in the current setting, we locally number the phases by the index $\boldsymbol{i}=\left[i_{1}, i_{2}, i_{3}\right]^{\top}$, see Fig. 2, where $\boldsymbol{i}=[2,3,0]^{\top}$ for the brick-C-S-H conglomerate and $\boldsymbol{i}=[4,5,0]^{\top}$ refers to a sand particle coated by ITZ. Now, we have

$$
A_{\mathrm{dil}, \mathrm{V}}^{\left(i_{1}\right)}=\frac{1}{Q_{11}^{2}}, \quad A_{\mathrm{dil}, \mathrm{V}}^{\left(i_{2}\right)}=\frac{Q_{11}^{1}}{Q_{11}^{2}},
$$

and

$$
\begin{aligned}
& A_{\mathrm{dil}, \mathrm{D}}^{\left(i_{1}\right)}=A_{1}-\frac{21}{5} \frac{R^{\left(i_{1}\right) 2}}{1-2 \nu^{\left(i_{1}\right)}} B_{1}, \\
& A_{\mathrm{dil}, \mathrm{D}}^{\left(i_{2}\right)}=A_{2}-\frac{21}{5} \frac{R^{\left(i_{2}\right) 5}-R^{\left(i_{2}-1\right) 5}}{\left(1-2 \nu^{\left(i_{2}\right)}\right)\left(R^{\left(i_{2}\right) 3}-R^{\left(i_{2}-1\right) 3}\right)} B_{2},
\end{aligned}
$$

where the auxiliary factors are provided in Appendix A.

\section{$2.2 \quad$ Stiffness estimates}

In Benveniste's [4] interpretation of the original MoriTanaka method [19], the mutual interaction among the heterogeneities is modeled by loading each particle by the average strain in the matrix phase $\boldsymbol{E}^{(0)}$ instead of $\boldsymbol{E}$. For this purpose, we relate $\boldsymbol{E}^{(0)}$ to $\boldsymbol{E}$ by a strain compatibility condition, valid under the dilute approximation,

$$
\boldsymbol{E}=\left(c^{(0)} \boldsymbol{I}+\sum_{r=1}^{n} c^{(r)} \boldsymbol{A}_{\mathrm{dil}}^{(r)}\right) \boldsymbol{E}^{(0)},
$$

from which we express the full concentration factors as

$$
\begin{aligned}
& \boldsymbol{A}^{(0)}=\left(c^{(0)} \boldsymbol{I}+\sum_{r=1}^{n} c^{(r)} \boldsymbol{A}_{\mathrm{dil}}^{(r)}\right)^{-1}, \\
& \boldsymbol{A}^{(r)}=\boldsymbol{A}_{\mathrm{dil}}^{(r)} \boldsymbol{A}^{(0)} \text { for } r=1, \ldots, n .
\end{aligned}
$$

Utilizing a universal relation

$$
\boldsymbol{L}_{\mathrm{eff}}=\sum_{r=0}^{n} c^{(r)} \boldsymbol{L}^{(r)} \boldsymbol{A}^{(r)},
$$

we can see that the effective stiffness inherits the symmetry of individual phases (1) with

$$
\begin{aligned}
K_{\mathrm{eff}} & =\frac{c^{(0)} K^{(0)}+\sum_{r=1}^{n} c^{(r)} K^{(r)} A_{\mathrm{dil}, \mathrm{V}}^{(r)}}{c^{(0)}+\sum_{r=1}^{n} c^{(r)} A_{\mathrm{dil}, \mathrm{V}}^{(r)}}, \\
G_{\mathrm{eff}} & =\frac{c^{(0)} G^{(0)}+\sum_{r=1}^{n} c^{(r)} G^{(r)} A_{\mathrm{dil}, \mathrm{D}}^{(r)}}{c^{(0)}+\sum_{r=1}^{n} c^{(r)} A_{\mathrm{dil}, \mathrm{D}}^{(r)}} .
\end{aligned}
$$

\subsection{Strength estimates}

As was first recognized by Kreher [14], the fluctuations of the stresses and strains in individual phases can be estimated from the energy conservation condition due to Hill [11]:

$$
\begin{aligned}
\boldsymbol{E}^{\top} \boldsymbol{L}_{\mathrm{eff}} \boldsymbol{E}= & \frac{1}{|\Omega|} \sum_{r=0}^{n}\left(9 K^{(r)} \int_{\Omega^{(r)}} \varepsilon_{\mathrm{V}}^{2}(\boldsymbol{x}) \mathrm{d} \boldsymbol{x}\right. \\
& \left.+\int_{\Omega^{(r)}} 2 G^{(r)} \varepsilon_{\mathrm{D}}^{\top}(\boldsymbol{x}) \varepsilon_{\mathrm{D}}(\boldsymbol{x}) \mathrm{d} \boldsymbol{x}\right)
\end{aligned}
$$

expressing the conservation of energy on the macroscale due to $\boldsymbol{E}$ and the average local values due to $\varepsilon_{\mathrm{V}}$ and $\varepsilon_{\mathrm{D}}$. Differentiating (8) with respect to $G^{(r)}$, we obtain

$$
\boldsymbol{E}^{\mathrm{\top}} \frac{\partial \boldsymbol{L}_{\mathrm{eff}}}{\partial G^{(r)}} \boldsymbol{E}=\frac{2}{|\Omega|} \int_{\Omega^{(r)}} \boldsymbol{\varepsilon}_{\mathrm{D}}^{\top}(\boldsymbol{x}) \varepsilon_{\mathrm{D}}(\boldsymbol{x}) \mathrm{d} \boldsymbol{x},
$$

for $r=0, \ldots, n$. Next, we recognize that $\boldsymbol{\sigma}_{\mathrm{D}}^{(r)}=$ $\left(1 / 2 G^{(r)}\right) \varepsilon_{\mathrm{D}}^{(r)}$ and recall the definition of the quadratic invariant (3) to arrive at

$$
J_{2}^{(r)}=G^{(r)} \sqrt{\frac{1}{c^{(r)}} \boldsymbol{E}^{\top} \frac{\partial \boldsymbol{L}_{\mathrm{eff}}}{\partial G^{(r)}}}
$$

As was thoroughly demonstrated by Pichler et al. [27] and Pichler and Hellmich [26], this quantity is closely related to the compressive strength $f_{\mathrm{c}}$ of 
Table 1: Reference properties of individual phases; $\rho$ denotes mass density, $f_{\mathrm{t}}$ is tensile strength, $m$ is the mass fraction, and radii $R$ are defined according to Fig. 2

\begin{tabular}{llcccccc}
\hline$r$ & Phase & $\begin{array}{c}\rho \\
{\left[\mathrm{kgm}^{-3}\right]}\end{array}$ & $\begin{array}{c}E \\
{[\mathrm{MPa}]}\end{array}$ & $\begin{array}{c}\nu \\
{[-]}\end{array}$ & $\begin{array}{c}f_{\mathrm{t}} \\
{[\mathrm{MPa}]}\end{array}$ & $\begin{array}{c}m \\
{[-]}\end{array}$ & $\begin{array}{c}R \\
{[\mu \mathrm{m}]}\end{array}$ \\
\hline 0 & Pure lime matrix & $1200^{\mathrm{a}}$ & $2000^{[8]}$ & $0.25^{[8]}$ & $0.4^{[8]}$ & 3 & $\times$ \\
\hline 1 & Voids & $\times$ & $10^{-9}$ & 0.25 & $\times$ & $\times$ & $0.1-100^{[22]} c^{(1)}=35 \%^{\mathrm{a}}$ \\
\hline 2 & Clay brick & $2300^{\mathrm{a}}$ & $5000^{\mathrm{a}}$ & $0.17^{\mathrm{a}}$ & $3.2^{\mathrm{a}}$ & 1 & 500 \\
\hline 3 & C-S-H gel & $2000^{[12]}$ & $22000^{[7]}$ & $0.2^{[7]}$ & $\times$ & $\times$ & $510^{[6]}$ \\
\hline 4 & Siliceous sand & $2700^{\mathrm{a}}$ & $60000^{[34]}$ & $0.17^{[34]}$ & $48^{[23]}$ & 1 & 500 \\
\hline 5 & ITZ & $1200^{\mathrm{b}}$ & $500^{\mathrm{c}}$ & $0.25^{\mathrm{b}}$ & $\times$ & $\times$ & $520^{\mathrm{c}}$ \\
\hline
\end{tabular}

${ }^{a}$ Our own (unpublished) data. Densities and porosity were measured by a pycnometer, elastic constants were determined from strain-gauge data in a compression test, and the tensile strength follows from a unidirectional tensile test.

b Same value as for the lime matrix.

c Set as in [36] for cement-based concretes, i.e., Young's modulus to 20-40\% of the value for the matrix phase and thickness to $20 \mu \mathrm{m}$.

cement pastes at various degrees of hydration. Here, we postulate that

$$
\frac{f_{\mathrm{c}}\left(p_{1}\right)}{f_{\mathrm{c}}\left(p_{2}\right)} \approx \frac{J_{2}^{(w)}\left(p_{2}\right)}{J_{2}^{(w)}\left(p_{1}\right)}
$$

where $w=0, \ldots, n$ is the index of the weakest phase and $p$ refers to a parameter characterizing the mixture composition, see the next section for concrete examples.

\section{Results and discussion}

The purpose of this section is to examine the trends in mechanical properties as predicted by the proposed scheme. The default data for individual phases, summarized in Table 1, were assembled from open literature and complemented with our own, yet unpublished, measurements. Note that the matrix-brick-sand fractions correspond to a typical composition of historic lime mortars $[3,2]$, and that the engineering constants $E$ and $\nu$ are connected to the bulk and shear moduli through well-known relations, e.g. [18, p. 23],

$$
K=\frac{E}{3(1-2 \nu)}, \quad G=\frac{E}{2(1+\nu)} .
$$

Given the data in Table 1, the volume fractions of individual phases are determined from six independent conditions. The first two relate the volume fractions of brick and sand particles and their coatings by

$$
c^{(3)}=\left(\left(\frac{R^{(3)}}{R^{(2)}}\right)^{3}-1\right) c^{(2)}, \quad c^{(5)}=\left(\left(\frac{R^{(5)}}{R^{(4)}}\right)^{3}-1\right) c^{(4)} .
$$

Next, we enforce the value of mass fractions via

$$
c^{(0)}=\frac{m^{(0)} \rho^{(2)}}{m^{(2)} \rho^{(0)}} c^{(2)}, \quad c^{(0)}=\frac{m^{(0)} \rho^{(4)}}{m^{(4)} \rho^{(0)}} c^{(4)},
$$

where $m^{(r)}$ and $\rho^{(r)}$ denote the mass fraction and the mass density of the $r$-th phase, respectively. Since $c^{(1)}$ is given, the remaining condition is provided by $\sum_{r=0}^{5} c^{(r)}=1$, and the phase volume fractions follow as the solution of the system of $6 \times 6$ linear equations.

In the sensitivity analyses, motivated by experimental findings in e.g. [3, 33, 32], we assume that an increase in the $\mathrm{C}-\mathrm{S}-\mathrm{H}$ gel volume fraction $\left(\Delta c^{(3)}\right)$ is compensated by the corresponding changes for matrix $\left(\Delta c^{(0)}\right)$, voids $\left(\Delta c^{(1)}\right)$, and clay bricks $\left(\Delta c^{(2)}\right)$, so that

$$
\Delta c^{(0)}+\Delta c^{(1)}+\Delta c^{(2)}+\Delta c^{(3)}=0,
$$

where we set for simplicity $\Delta c^{(1)}=\Delta c^{(2)}=\Delta c^{(3)}$. By analogy, the increase in the volume fraction of ITZ corresponds to the decrease in volume of the matrix phase:

$$
\Delta c^{(0)}+\Delta c^{(5)}=0 .
$$

In the strength estimates, the imposed loading simulates the uniaxial compression test, for which $\boldsymbol{\Sigma}=[-1,0,0,0,0,0]^{\top}$ and the average strain follows from

$$
\boldsymbol{E}=\left(\boldsymbol{L}_{\mathrm{eff}}\right)^{-1} \boldsymbol{\Sigma} .
$$

We assume that ITZ is the weakest phase, i.e. $w=5$ in Eq. (10), and, similarly to [27], we estimate the derivative in Eq. (9) by the forward difference with a step size of $\Delta G^{(5)}=1 \mathrm{~Pa}^{1}$

\footnotetext{
${ }^{1}$ Our results are reproducible with a MATLAB code Homogenizator MT, freely available at http://mech.fsv.cvut . $\mathrm{cz/ \sim nezerka/software.}$
} 

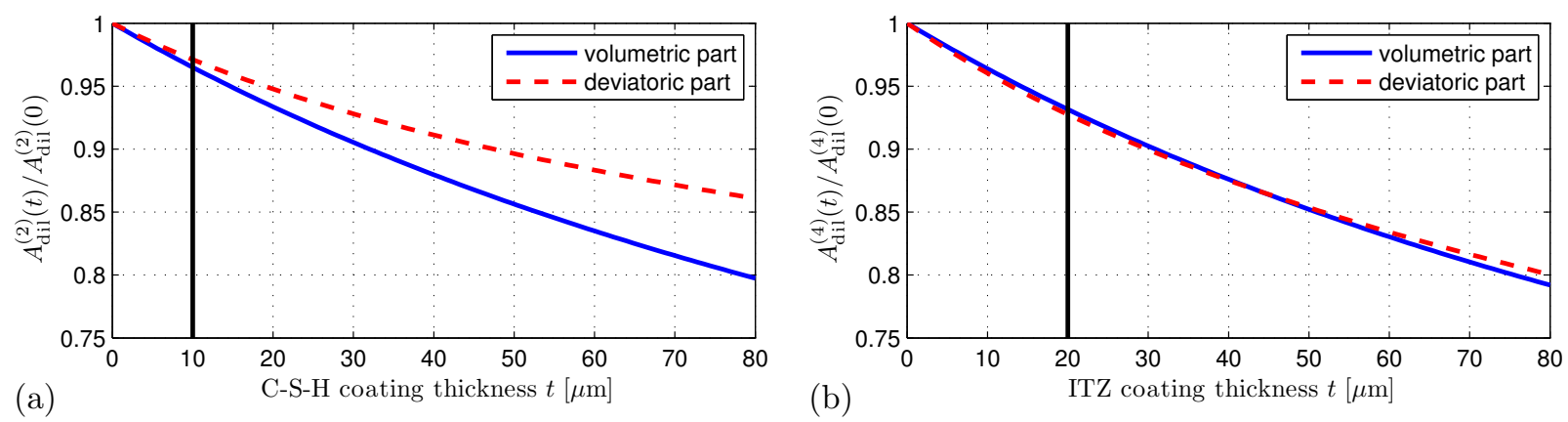

Figure 3: Influence of the coating thickness on the dilute concentration factors for (a) brick and (b) sand particles. The vertical lines refer to the default thicknesses that are kept constant in the remaining sensitivity analyses.
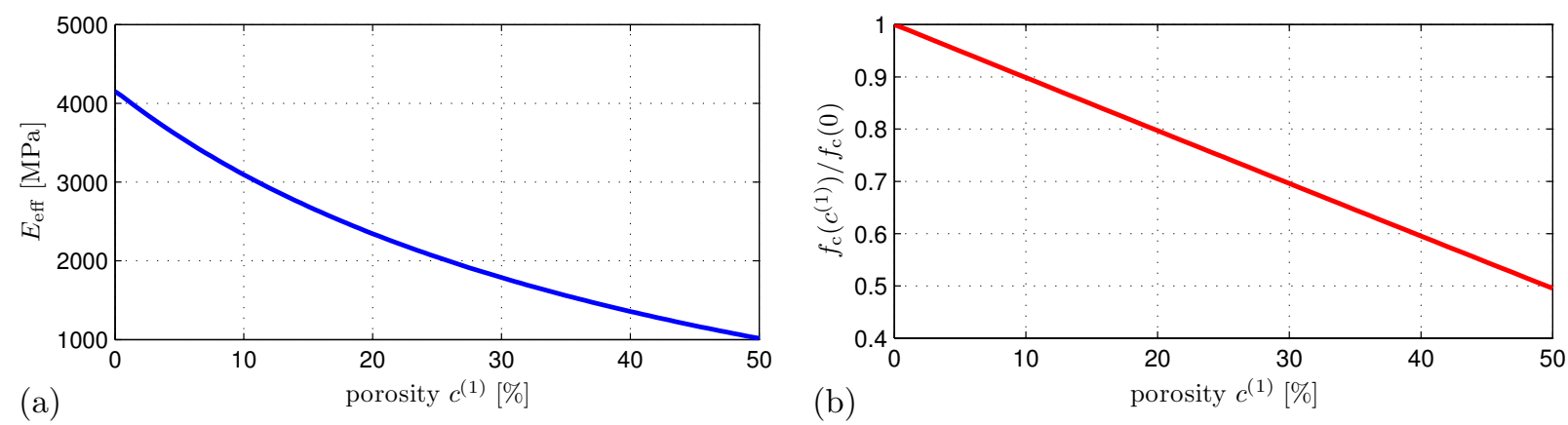

Figure 4: (a) Stiffness-porosity and (b) strength-porosity relations.

\subsection{Effect of coatings}

The first aspect that we would like to discuss is the effect of the coating on the dilute concentration factors of the brick and sand particles. Fig. 3 demonstrates that, in terms of the volumetric phase strains, the effects of C-S-H and ITZ are comparable, despite the fact that the C-S-H is stiffer and ITZ is more compliant than the matrix phase. The differences in the deviatoric part, which drive the strength estimates according to Eq. (10), become more pronounced with the increasing thickness. This indicates that the contribution of brick and sand particles to the overall properties might still be different, after accounting phase properties and their interaction, see Section 3.3 for a further discussion.

\subsection{Influence of porosity}

By analogy with the cement pastes, porosity has a major influence on the overall properties of lime-based mortars. This is confirmed by the results of the proposed model, shown in Fig. 4. As for the overall stiffness, for the realistic range of porosities of 25$40 \%$ [8], the estimates (7) predict Young modulus values between $\approx 2,000$ and $1,000 \mathrm{MPa}$. This is consistent with the values reported in [3] historic lime mortars (without pozzolan admixtures).

As for the strength estimates, it follows from Fig. 4 (b) that they reproduce a Power-law relation [23, p. 280]

$$
f_{\mathrm{c}}\left(c^{(1)}\right)=f_{\mathrm{c}}(0)\left(1-c^{(1)}\right)^{n},
$$

with $n \doteq 1.04$, yielding practically the linear strengthporosity scaling. Unfortunately, we are currently unable to validate this prediction against experiments; the only available work we are aware of by Papayianni and Stefanidou [25] does not contain enough data. Still, Eq. (11) complies with the fact that the influence of porosity is much smaller in lime mortars than in cement-based materials [15, Section 2.6], for which $n \approx 3$ is typically used, see [25, and references therein].

\subsection{Size effects}

Now we proceed to clarify the impact of brick and sand particles on the overall mechanical properties. ${ }^{2}$ In particular, when the size of the brick particles increases, the material becomes more compliant since the stiffening effect of the C-S-H layer decreases, Fig. 5(a). This also increases the deviatoric stresses in ITZ, as manifested by the strength reduction visible in Fig. 5(b). These effects practically stabilize for particles larger than $0.5 \mathrm{~mm}$, and their magnitude is rather limited: the stiffness decreases by about $10 \%$ and the strength only by $4 \%$. Such trends are qualitatively consistent with the results presented e.g. in [3, 21, 29].

Larger sand particles, on the other hand, tend to make the composite material stiffer, Fig. 6(a), by

\footnotetext{
${ }^{2}$ In the sensitivity analysis, the mass ratio is kept constant according to Table 1 .
} 


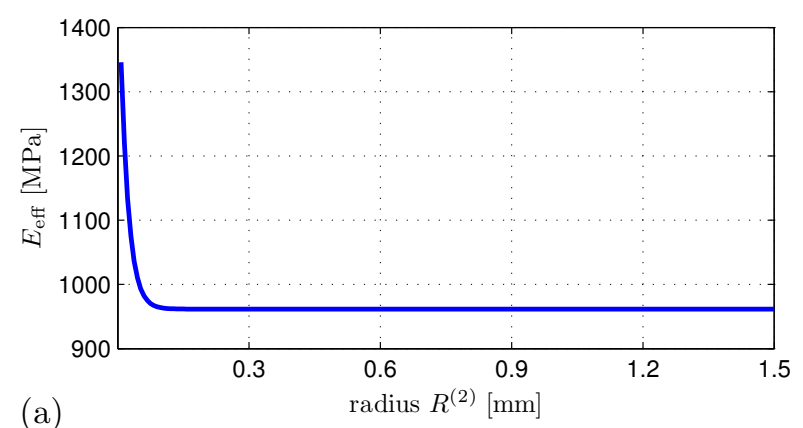

Figure 5: Influence of the brick particle size on the overall (a) stiffness and (b) strength.

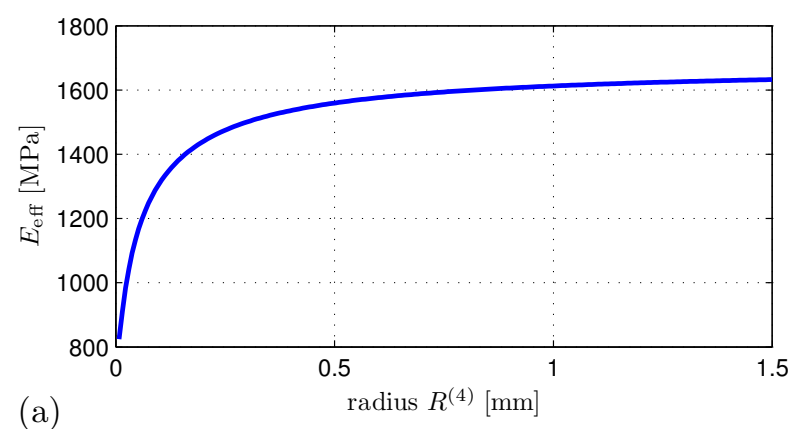

Figure 6: Influence of the sand particle size on the overall (a) stiffness and (b) strength.

compensating for the inferior mechanical properties of the ITZ. Since the relative thickness of ITZ layer decreases, the stresses inside this phase increase and the material becomes weaker in overall, Fig. 6(b). When compared to brick particles, these effects are much more pronounced: in the considered range of radii, the Young modulus increases by about $100 \%$ and the strength decreases by $25 \%$ with no tendency to stabilize. This agrees well with the experimental outcomes reported in [30].

\section{Conclusions}

In the present work, following the recent developments presented in [27, 26, 35, 34], a simple micromechanicsbased scheme for strength and stiffness estimates of cocciopesto mortars has been presented. The model directly utilizes measurable material and geometrical properties of individual phases and is free of adjustable parameters. On the basis of the presented results, we conclude that the model

1. predicts realistic values of the overall Young modulus and strength-porosity scaling,

2. captures the "smaller is stiffer" and "smaller is stronger" trends for crushed brick particles,

3. captures the "larger is stiffer" and "larger is weaker" trends for sand aggregates,

4. explains the positive role of crushed bricks in comparison with sand aggregates.
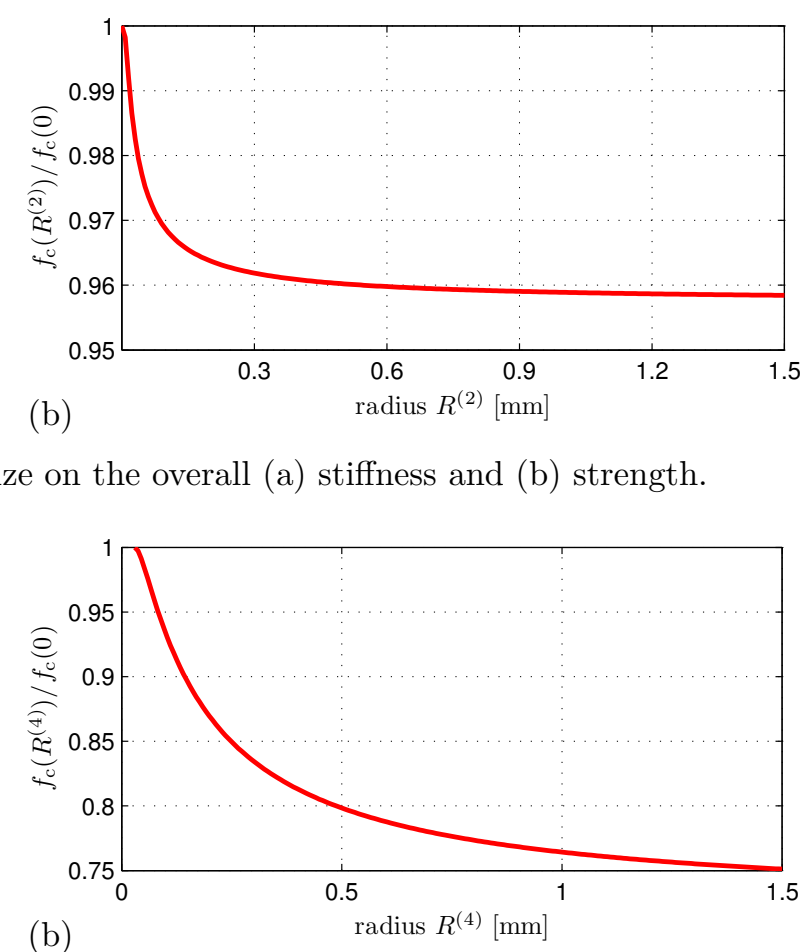

(b)

Of course, in order for this model to be accepted for practical use, it needs to be validated against comprehensive experimental data at micro- and macroscales, and the role of ITZ in lime-based mortars needs to be clarified. This topic is currently under investigation and will be reported separately.

\section{Acknowledgements}

We wish to thank an anonymous referee for a number of valuable suggestions on the previous version of the manuscript. This work was supported by the Ministry of Culture of the Czech Republic, project No. DF11P01OVV008.

References appear after the appendix on page 36 . 
The effect of coating on the mechanical properties enters the solution through the auxiliary factors $\boldsymbol{Q}^{k}$ in Eq. (5), and $\boldsymbol{A}^{k}$ and $\boldsymbol{B}^{k}$ in Eq. (6). Here, these are provided in the closed form optimized for coding, utilizing the results and nomenclature by Herve and Zaoui [10]. Note that in order to keep the notation consistent, $a^{(k)}$ corresponds to a property of the $k$-th phase, whereas $a^{k}$ denotes a quantity utilized in the Herve-Zaoui solution (independent of $\left.a^{(k)}\right)$. Also recall that we employ the local numbering of phases by the index $\boldsymbol{i}=\left[i_{1}, i_{2}, i_{3}\right]^{\top}$ introduced by Fig. 2 . In particular, the volumetric part is expressed in terms of matrices

$$
Q^{1}=N^{1}, \quad Q^{2}=N^{2} Q^{1}
$$

with

$$
\boldsymbol{N}^{k}=\frac{1}{3 K^{\left(i_{k+1}\right)}+G^{\left(i_{k+1}\right)}}\left[\begin{array}{cc}
3 K^{\left(i_{k}\right)}+4 G^{\left(i_{k+1}\right)} & \frac{4}{R^{\left(i_{k}\right) 3}}\left(G^{\left(i_{k+1}\right)}-G^{\left(i_{k}\right)}\right) \\
3 R^{\left(i_{k}\right) 3}\left(K^{\left(i_{k+1}\right)}-K^{\left(i_{k}\right)}\right) & 3 K^{\left(i_{k+1}\right)}+4 G^{\left(i_{k}\right)}
\end{array}\right] \text { for } k=1,2 .
$$

The matrices needed to evaluate the deviatoric part follow from

$$
\boldsymbol{A}^{1}=\frac{P_{22}^{2}}{P_{11}^{2} P_{22}^{2}-P_{12}^{2} P_{21}^{2}}, \quad \boldsymbol{A}^{2}=W_{1}^{2}, \quad \boldsymbol{B}^{1}=\frac{-P_{21}^{2}}{P_{11}^{2} P_{22}^{2}-P_{12}^{2} P_{21}^{2}}, \quad \boldsymbol{B}^{2}=W_{2}^{2},
$$

where

$$
\boldsymbol{W}^{k}=\frac{1}{P_{22}^{2} P_{11}^{2}-P_{12}^{2} P_{21}^{2}} \boldsymbol{P}^{k-1}\left[\begin{array}{llll}
P_{22}^{2} & -P_{21}^{2} & 0 & 0
\end{array}\right]^{\top}(k=1,2), \quad \boldsymbol{P}^{1}=\boldsymbol{M}^{1}, \quad \boldsymbol{P}^{2}=\boldsymbol{M}^{2} \boldsymbol{P}^{1}
$$

The auxiliary matrix $\boldsymbol{M}^{k}$ admits the expression:

$$
\boldsymbol{M}^{k}=\frac{1}{5\left(1-\nu^{\left(i_{k+1}\right)}\right)}\left[\begin{array}{cccc}
\frac{c^{k}}{3} & \frac{R^{\left(i_{k}\right) 2}\left(3 b^{k}-7 c^{k}\right)}{5\left(1-2 \nu^{\left(i_{k}\right)}\right)} & \frac{-12 \alpha^{k}}{R^{\left(i_{k}\right) 5}} & \frac{4\left(f^{k}-27 \alpha^{k}\right)}{15 R^{\left(i_{k}\right) 3}\left(1-2 \nu^{\left(i_{k}\right)}\right)} \\
0 & \frac{b^{k}\left(1-2 \nu^{\left(i_{k+1}\right)}\right)}{5\left(1-2 \nu^{\left(i_{k}\right)}\right)} & M_{23}^{k} & \frac{-12 \alpha^{k}\left(1-2 \nu^{\left(i_{k+1}\right)}\right)}{7 R^{\left(i_{k}\right) 7}\left(1-2 \nu^{\left(i_{k}\right)}\right)} \\
\frac{R^{\left(i_{k}\right) 5} \alpha^{k}}{2} & \frac{-R^{\left(i_{k}\right) 7}\left(2 a^{k}+147 \alpha^{k}\right)}{70\left(1-2 \nu^{\left(i_{k}\right)}\right)} & \frac{d^{k}}{7} & M_{34}^{k} \\
M_{41}^{k} & \frac{7 \alpha^{k} R^{\left(i_{k}\right) 5}\left(1-2 \nu^{\left(i_{k+1}\right)}\right)}{2\left(1-2 \nu^{\left(i_{k}\right)}\right)} & 0 & \frac{e^{k}\left(1-2 \nu^{\left(i_{k+1}\right)}\right)}{3\left(1-2 \nu^{\left(i_{k}\right)}\right)}
\end{array}\right]
$$

with

$$
\begin{array}{ll}
M_{23}^{k} & =\frac{-20 \alpha^{k}\left(1-2 \nu^{\left(i_{k+1}\right)}\right)}{7 R^{\left(i_{k}\right) 7}}, \\
M_{34}^{k} & =\frac{R^{\left(i_{k}\right) 2}\left(105\left(1-\nu^{\left(i_{k+1}\right)}\right)+12 \alpha^{k}\left(7-10 \nu^{\left(i_{k+1}\right)}\right)-7 e^{k}\right)}{35\left(1-2 \nu^{\left(i_{k}\right)}\right)},
\end{array}
$$

and

$$
\begin{aligned}
a^{k} & =\frac{G^{\left(i_{k}\right)}}{G^{\left(i_{k+1}\right)}}\left(7+5 G^{\left(i_{k}\right)}\right)\left(7-10 G^{\left(i_{k+1}\right)}\right)-\left(7-10 G^{\left(i_{k}\right)}\right)\left(7+5 G^{\left(i_{k+1}\right)}\right), \\
b^{k} & =\frac{G^{\left(i_{k}\right)}}{G^{\left(i_{k+1}\right)}}\left(7+5 G^{\left(i_{k}\right)}\right)+4\left(7-10 G^{\left(i_{k}\right)}\right), \\
c^{k} & =\left(7-5 G^{\left(i_{k+1}\right)}\right)+2\left(4-5 G^{\left(i_{k+1}\right)}\right) \frac{G^{\left(i_{k}\right)}}{G^{\left(i_{k+1}\right)}} \\
d^{k} & =\left(7+5 G^{\left(i_{k+1}\right)}\right)+4\left(7-10 G^{\left(i_{k+1}\right)}\right) \frac{G^{\left(i_{k}\right)}}{G^{\left(i_{k+1}\right)}} \\
e^{k} & =2\left(4-5 G^{\left(i_{k}\right)}\right)+\frac{G^{\left(i_{k}\right)}}{G^{\left(i_{k+1}\right)}}\left(7-5 G^{\left(i_{k}\right)}\right) \\
f^{k} & =\left(4-5 G^{\left(i_{k}\right)}\right)\left(7-5 G^{\left(i_{k+1}\right)}\right)-\frac{G^{\left(i_{k}\right)}}{G^{\left(i_{k+1}\right)}}\left(4-5 G^{\left(i_{k+1}\right)}\right)\left(7-5 G^{\left(i_{k}\right)}\right), \\
\alpha^{k} & =\frac{G^{\left(i_{k}\right)}}{G^{\left(i_{k+1}\right)}}-1 .
\end{aligned}
$$

Appendix A: Herve-Zaoui solution 


\section{References}

[1] A. Arizzi, G. Cultrone. Aerial lime-based mortars blended with a pozzolanic additive and different admixtures: A mineralogical, textural and physical-mechanical study. Construction and Building Materials 31:135-143, 2012.

[2] G. Baronio, L. Binda. Study of the pozzolanicity of some bricks and clays. Construction and Building Materials 11:41-46, 1997.

[3] G. Baronio, L. Binda, N. Lombardini. The role of brick pebbles and dust in conglomerates based on hydrated lime and crushed bricks. Construction and Building Materials 11:33-40, 1997.

[4] Y. Benveniste. A new approach to the application of Mori-Tanaka theory in composite materials. Mechanics of Materials 6:147-157, 1987.

[5] O. Bernard, Ulm F.-J., E. Lemarchand. A multiscale micromechanics-hydration model for the early-age elastic properties of cement-based materials. Cement and Concrete Research 33:12931309, 2003.

[6] H. Böke, S. Akkurt, B. Ípekoğlu, E. Uğurlu. Characteristics of brick used as aggregate in historic brick-lime mortars and plasters. Cement and Concrete Research 36:1115-1122, 2006.

[7] G. Constantinides, F.J. Ulm. The effect of two types of C-S-H on the elasticity of cement-based materials: Results from nanoindentation and micromechanical modeling. Cement and Concrete Research 34:67-80, 2004.

[8] M. F. Drdácký, D. Michoinová. Lime mortars with natural fibres. In A. M. Brandt, V. C. Li, I. H. Marshall (eds.), Brittle Matrix Composites \%: Proceedings of the 7th International Symposium, pp. 523-532. Institute of Fundamental Technological Research, Woodhead Publishing Limited, Cambridge, UK, 2003.

[9] J.D. Eshelby. The Determination of the Elastic Field of an Ellipsoidal Inclusion, and Related Problems. Proceedings of the Royal Society of London 241:376-396, 1957.

[10] E. Herve, A. Zaoui. n-layered inclusion-based micromechanical modelling. International Journal of Engineering Science 31:1-10, 1993.

[11] R. Hill. Elastic properties of reinforced solids: Some theoretical principles. Journal of the $\mathrm{Me}$ chanics and Physics of Solids 11(5):357-372, 1963.
[12] J.T. Jeffrey, M.J. Hamlin. A colloidal interpretation of chemical aging of the C-S-H gel and its effects on the properties of cement paste. Cement and Concrete Research 36:30-38, 2006.

[13] M. Jirásek. Basic concepts and equations of solid mechanics. Revue Européenne de Génie Civil 11:879-892, 2007.

[14] W. Kreher. Residual stresses and stored elastic energy of composites and polycrystals. Journal of the Mechanics and Physics of Solids 38:115-128, 1990.

[15] R.M.H. Lawrence. A study of carbonation in nonhydraulic lime mortars. Ph.D. thesis, University of Bath, 2006.

[16] P. Maravelaki-Kalaitzaki, A. Bakolas, A. Moropoulou. Physico-chemical study of Cretan ancient mortars. Cement and Concrete Research 33:651-661, 2003.

[17] D. Michoniová. Questions about renovation plasters. Zprávy památkové péče 65:313-316, 2005. In Czech.

[18] G. W. Milton. The Theory of Composites. Cambridge Monographs on Applied and Computational Mathematics. Cambridge University Press, 2002.

[19] T. Mori, Tanaka K. Average stress in matrix and average elastic energy of materials with mixfitting inclusions. Acta Metallurgica 21:571-574, 1973.

[20] A. Moropoulou, A. Bakolas, K. Bisbikou. Characterization of ancient, Byzantine and later historic mortars by thermal and X-ray diffraction techniques. Thermochemica Acta 269/270:779-995, 1995.

[21] A. Moropoulou, A.S. Cakmak, G. Biscontin, et al. Advanced Byzantine cement based composites resisting earthquake stresses: the crushed brick/lime mortars of Justinian's Hagia Sophia. Construction and Building Materials 16(8):543$552,2002$.

[22] M.J. Mosquera, B. Silva, B. Prieto, E. RuizHerrera. Addition of cement to lime-based mortars: Effect on pore structure and vapor transport. Cement and Concrete Research 36:1635-1642, 2006.

[23] A.M. Neville. Properties of Concrete: Fourth Edition. Longman, 1996.

[24] J.P. Ollivier, J. C. Maso, B. Bourdette. Interfacial transition zone in concrete. Advanced Cement Based Materials 2:30-38, 1995. 
[25] I. Papayianni, M. Stefanidou. Strength-porosity relationships in lime-pozzolan mortars. Construction and Building Materials 20:700-705, 2005.

[26] B. Pichler, C. Hellmich. Upscaling quasi-brittle strength of cement paste and mortar: A multiscale engineering mechanics model. Cement and Concrete Research 41:467-476, 2011.

[27] B. Pichler, C. Hellmich, J. Eberhardsteiner. Spherical and acicular representation of hydrates in a micromechanical model for cement paste: prediction of early-age elasticity and strength. Acta Mechanica 203(3):137-162, 2009.

[28] K.L. Scrivener, A.K. Crumbie, P. Laugesen. The interfacial transition zone (ITZ) between cement paste and aggregate in concrete. Interface Science 12:411-421, 2004.

[29] A. Sepulcre-Aguilar, F. Hernández-Olivares. Assessment of phase formation in lime-based mortars with added metakaolin, Portland cement and sepiolite, for grouting of historic masonry. Cement and Concrete Research 40:66-76, 2010.

[30] M. Stefanidou, I. Papayianni. The role of aggregates on the structure and properties of lime mortars. Cement $\&$ Concrete Composites 27:914919, 2005.
[31] J. Stránský, J. Vorel, J. Zeman, M. Šejnoha. Mori-Tanaka based estimates of effective thermal conductivity of various engineering materials. Micromachines 2:129-149, 2011.

[32] E. Vejmelková, M. Keppert, Z. Keršner, et al. Mechanical, fracture-mechanical, hydric, thermal, and durability properties of lime-metakaolin plasters for renovation of historical buildings. Construction and Building Materials 31:22-28, 2012.

[33] A.L. Velosa, F. Rocha, R. Veiga. Influence of chemical and mineralogical composition of metakaolin on mortar characteristics. Acta Geodynamica et Geomaterialia 153:121-126, 2009.

[34] J. Vorel, V. Śmilauer, Z. Bittnar. Multiscale simulations of concrete mechanical tests. Journal of Computational and Applied Mathematics 236:4882-4892, 2012.

[35] V. Šmilauer, P. Hlaváček, F. Škvára, et al. Micromechanical multiscale model for alkali activation of fly ash and metakaolin. Journal of Materials Science 46:6545-6555, 2011.

[36] C.C. Yang. Effect of the transition zone on the elastic moduli of mortar. Cement and Concrete Research 28:727-736, 1998.

[37] A. Zaoui. Continuum micromechanics: Survey. Journal of Engineering Mechanics 128:808-816, 2002 . 